\title{
The Effect of Operational Mechanisms on Creativity in Design
}

\author{
Andrew Warr and Eamonn O’Neill \\ Human-Computer Interaction Group, Department of Computer Science, \\ University of Bath, Bath, UK \\ +44 (0) $12253374 / 3216$ \\ \{cspaw, eamonn\} acs.bath.ac.uk
}

\begin{abstract}
Creativity is frequently referred to as an important dynamic of design. However, over 50 years of empirical research has suggested that social influences have a detrimental effect on creativity in collaborating groups. The results of this research indicate that design teams may not be as creative as they could be, resulting in a negative impact on the design process. In this paper we build upon previous research to identify what effect operational mechanisms have on creativity, in order to determine how best to support the creative process in design.
\end{abstract}

\section{Introduction}

The Human Computer Interaction (HCI) community has long been concerned with the design of usable software applications and computer systems. Over the years a consensus has developed that involving users directly in the software development process can lead to more useful and usable systems. This has found its clearest expression in the Participatory Design (PD) movement. PD initially grew out of Scandinavian concerns to bring democracy into the work place [1], by involving users in the design stage of the software development process. Since the 1970s, the focus of PD has shifted from introducing democracy into the work place to a belief that 'active user involvement in the software development process leads to more useful and usable software products' [2]. PD epitomizes the collaborative nature of design, bringing together stakeholders from diverse backgrounds to work together in both the analytical and creative practices of systems development. Design in PD is a social rather than an individual activity. However, even in design processes that do not encourage user participation, an individual designer rarely works in isolation.

The collaborative processes of generating design requirements and envisioned system designs remain something of a 'magic art', within both PD and other systems development approaches. In the PD literature, this 'magic art' is frequently referred to using terms such as creativity and innovation [e.g. 2-8]. However, while participatory design may be viewed as a collaborative or social creative process and PD researchers and practitioners use the term 'creativity' when referring to the design process, they provide little definition of what this term means and what is actually involved in this process of social creativity, although many researchers [e.g. 9, 10] have argued the importance of creativity in design. 
In our research $[11,12]$ we have built upon previous research in creativity [e.g. 1315], to develop a unified definition of creativity:

'Creativity is the generation of ideas, which are a combination of two or more matrices of thought, which are considered unusual or new to the mind in which the ideas arose and are appropriate to the characteristics of a desired solution defined during the problem definition and preparation stage of the creative process'.

With respect to design, creativity is the generation of design ideas, to solve a given design problem, which are both: (i) new or unusual to the mind in which they arose (novelty); and (ii) conform to the requirements of the design problem (appropriateness).

In this paper, we report the results of an experiment we conducted to investigate creativity in design; specifically, we investigated the effect of operational mechanisms (i.e. altering the group composition in the design process) on creativity for both individuals and groups. Many researchers [e.g. 16] have studied the effects on creativity due to procedural mechanisms (i.e. production blocking); social psychological mechanisms (i.e. evaluation apprehension); and economic mechanisms (i.e. free-riding). We extend this consideration to include a fourth type: operational mechanisms. We define operational mechanisms to include, for example, group size and group composition. Building upon previous research we discuss the findings of our experiment observing the effect on creativity due to the operational mechanism of group composition, and provide a focus for future research on supporting creativity in design.

\section{Experiment Overview}

In 1958 Taylor et al [9] conducted a study comparing real groups (i.e. face-to-face interacting groups) with nominal groups (i.e. individuals working on their own and then collating their outputs to form a cumulative output), to test Osborn's claim that 'the average person can think up twice as many ideas when working within a group than when working alone' [17]. Taylor et al found that nominal groups produced nearly twice as many non-replicated ideas as real groups - refuting Osborn's claim. Since the Taylor et al study, over 50 years of empirical studies have shown nominal groups to outperform real groups. Hence, Taylor et al and other researchers have shown that collaborating groups, such as design teams, are not being as creative as they could be.

Since the Taylor et al [9] study, there has been an abundance of research investigating why real groups are not as effective as nominal groups with respect to creativity [e.g. 18]. However, the findings of such research have only increased the effectiveness of creativity in real groups over nominal groups slightly in some conditions, while there are still many cases where nominal groups outperform real groups. Therefore some researchers [e.g. 18, 19] have suggested that the process of idea generation should be performed by nominal groups alone.

Rotter et al [20] conducted a study observing the effects on creativity due to different group compositions in the design process (i.e. operational mechanisms). Rotter et al [20] hypothesized that the number of solutions would be greater when participants worked consecutively in an individual and a group setting (nominal-real 
or real-nominal conditions) rather than either a group (real condition) or an individual (nominal condition) setting alone. It was also hypothesized that for all conditions the number of ideas generated should be greater when working individually than when working within a group. The first hypothesis was not supported, as there were significantly more ideas produced in the nominal condition than either of the mixed conditions or the real condition. Their second hypothesis was supported, showing nominal groups to be more creative than real groups.

However, the Rotter et al [20] study had a few fundamental flaws. In the individual condition the participants were told to write down their ideas. However, in the other conditions involving a group component the participants were also allowed to communicate verbally. This form of asynchronous interaction adds a variable of production blocking, resulting in a difference between the conditions [12]. Secondly, if group members can verbally express their ideas rather than just writing them down, a variable of evaluation apprehension is also introduced [12]. The resultant effect of these confounding variables between the conditions means that the results cannot be relied upon. In addition to this, in the nominal-real and real-nominal group conditions, the participants were not allowed to bring up ideas they had previously generated in the latter half of the experiment. According to our theory [12], if the externalization of matrices of thought (i.e. ideas) is prohibited, there is a resultant detrimental effect on creativity.

In our study it is hypothesized (H1) that the number of novel and creative ideas generated in response to a given design problem should be greater when participants work in a nominal-real condition rather than in a real, nominal or real-nominal condition. The rationale for this hypothesis is that an individual will initially (in the nominal sub-condition) be able to exploit the matrices of thought in her own domain of knowledge. Upon transferring to the real sub-condition, the participants in the group will be exposed to other matrices of thought allowing them to combine and generate new matrices of thought, or improve upon the ideas of others. Whereas in the real-nominal condition and the real group condition participants may be influenced by group norms [21], and in the nominal condition an individual will exhaust her domain of knowledge compared to those groups who have the ability to interact with each other and externalize their matrices of thought. It is also hypothesized (H2) that the nominal condition will generate more novel and creative replicated ideas compared to the other conditions and the real condition will generate fewer novel and creative replicated ideas compared to other conditions. Rotter et al [20] argued that the expression of an idea in a group causes all the members to think along the same lines, leading to the duplication of ideas. However, we argue that being in a setting which allows other members to see what ideas are being generated will cause less duplication as members are aware of what has already been reported.

\section{Method}

The experiment had a between participants experimental design. The experiment manipulated one independent variable, the operational mechanism of group composition, which consisted of four levels: 1) Nominal Groups; 2) Nominal-Real Groups; 3) Real-Nominal Groups; and 4) Real Groups. The dependent variable was 
creativity - the number of novel and appropriate design ideas generated [12]. It was predicted that: the number of novel and creative ideas generated in response to a given design problem would be greater when participants worked in the nominal-real condition rather than in a real, nominal or real-nominal condition (H1); and the nominal condition would generate more novel and creative replicated ideas compared to the other conditions and the real condition would generate fewer novel and creative replicated ideas compared to the other conditions (H2).

\subsection{Participants}

Forty-eight participants, seven of whom were female, took part in this experiment, twelve per condition. The participants varied in age from $18-37$, with a mean of 20.65 years. All participants were computer scientists from the University of Bath, with the majority of them being undergraduates. The participants were recruited personally by the experimenter from lecture rooms and mailing lists and were each paid $£ 5$ for participating in the experiment.

\subsection{Apparatus}

The set up of the apparatus can be seen in fig. 1. On each participant's desk was a 12" display IBM x31 ThinkPad and a USB Microsoft IR Mouse. Each of the ThinkPads' had an internal $802.11 \mathrm{~g}$ wireless connection which allowed it to communicate with a server. An A4 piece of paper was stuck to the desk, giving information relevant to the experiment: Osborn's four brainstorming rules, the rules of the experiment, and the design problem which was covered by an overlay until the experiment started (see Sect. 3.3). Each participant's desk was shielded by tall dividers to prevent communication between participants.

Each ThinkPad was running a custom built stand-alone Windows application - the Idea Generator (see fig. 2). In the top right of the screen is the generated ideas textbox - this is where a participant writes her idea when she thinks of one. To submit an idea, participants could either press the 'submit' button located in the bottom right of the screen, or press the 'enter' key on the keyboard. The generated ideas textbox could be cleared by pressing the 'clear' button in the bottom right of the screen. In the bottom

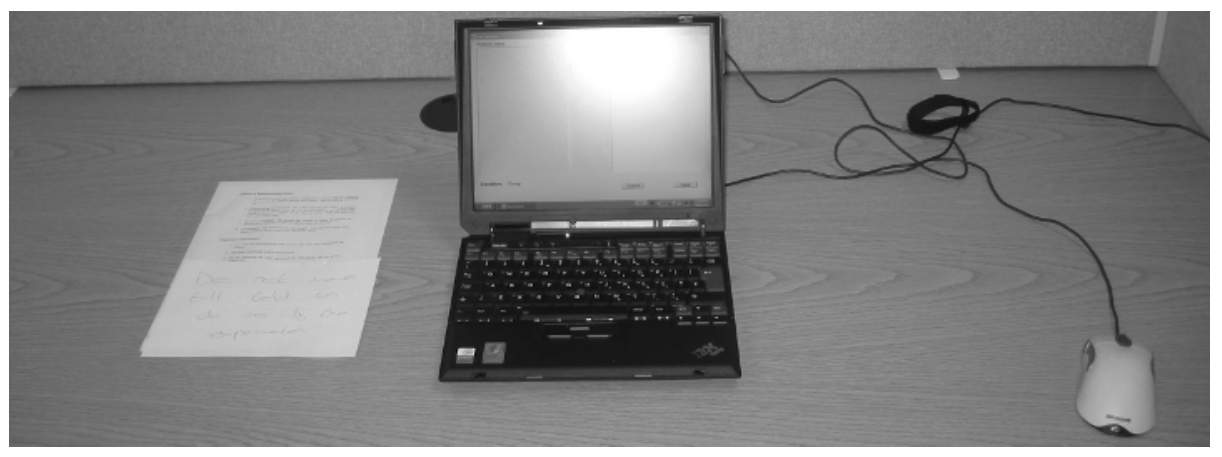

Fig. 1. Experimental set up on a Participant's Desk 
left of the screen is a condition label that indicates to the user which condition they are currently in - individual (i.e. nominal) or group (i.e. real). In the top left of the screen is the pooled ideas textbox. This textbox displayed recorded ideas dependent on the current condition and could not be edited. In the nominal condition, only the participant's own ideas could be viewed. In the real condition, all participants could see the ideas generated by themselves and others. In the nominal-real condition, when the condition changed from the nominal sub-condition to the real sub-condition all ideas generated by each participant during the nominal sub-condition were pooled into the pooled ideas textbox. In the real-nominal condition, when the sub-condition changed from the real sub-condition to the nominal sub-condition, all ideas generated by the group during the real sub-condition remained in the pooled ideas textbox during the nominal sub-condition.

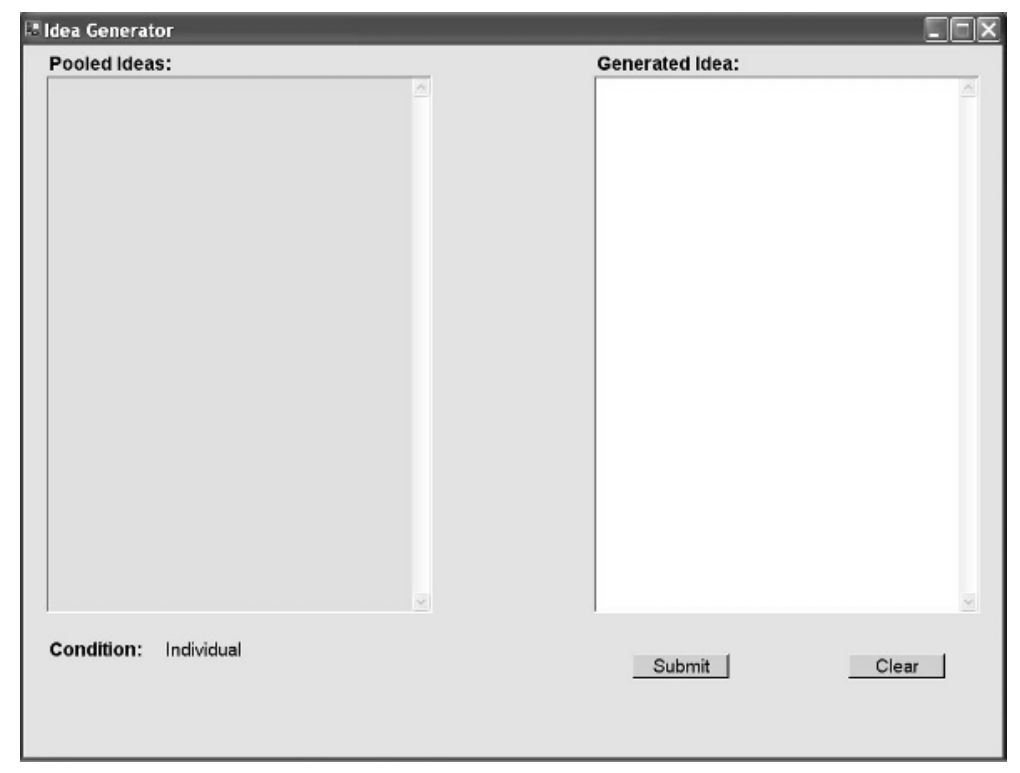

Fig. 2. Idea Generator Software

In a separate room to the experiment was the experimenter's table. The experiment was recorded here. In the participants' room were two cameras which each viewed two participants. The output from these cameras was fed through a monitor displaying a real-time image to the experimenter. The image was also captured via a DVC recorder for future analysis. The experimenter also had access to a HP Tablet PC that ran the Windows Remote Desktop application to access the server remotely. This allowed the experimenter to change the sub-condition during the nominal-real and real-nominal experimental conditions.

The server was a standard desktop PC that ran Microsoft's SQL Enterprise Server version 8.0. An SQL database ran on this server, storing ideas generated by the participants and other information: who generated the idea; the condition in which the 
idea was generated; and the date and time the idea was recorded. The server was also used to play audio files of instructions to the participants via Windows Media Player.

\subsection{Procedure}

Participants were run in groups of four in a secure, sound-proof lab. At the outset the participants were taken to the back of the lab where the pre-recorded instructions were played. Pre-recorded instructions were used to minimise the experimenter's contact with the participants. The start of the pre-recordings gave an overview of the experiment: the condition the participants had been assigned to; a description of Osborn's brainstorming rules; some rules to abide by during the experiment; a description of the software; the warm-up exercise; and the design problem for the actual experiment. After each audio file the experimenter asked the participants if they had any questions and tried to answer them to best of his ability. Creativity was never mentioned, as Amabile [14] argues that participants' performance changes if they are aware that they are being assessed on creativity.

The groups were assigned to one of four conditions:

1) Nominal Condition: Participants work individually for 16 minutes.

2) Nominal-Real Condition: Participants work individually for 8 minutes and then as a group for 8 minutes.

3) Real-Nominal Condition: Participants work as a group for 8 minutes and then individually for 8 minutes.

4) Real Condition: Participants work as a group for 16 minutes.

Osborn's brainstorming rules were given to the participants to help them with the idea generation process:

1) Criticism is ruled out. Adverse judgement of ideas must be withheld. No one shall criticism anyone else's ideas. Say anything you think of.

2) Freewheeling is welcomed. The wilder the idea the better. It is easier to tame down than think up. Do not be afraid to say anything that comes to mind. The further out the idea the better, this will stimulate more and better ideas.

3) Quantity is wanted. The greater the number of ideas, the greater the likelihood of winners. Come up with as many as you can.

4) Combination and improvement are sought. Suggest how the ideas of others can be joined into still better ideas.

In contrast to previous experiments, these brainstorming rules were included on the information sheet attached to each participant's desk. This was done to relieve the cognitive load on each participant, so that they could focus more on the design problem at hand.

Based on previous research [18], participants were told three rules by which to abide in order to control confounding variables:

1) You may not communicate with anyone else once the experiment has started - to control production blocking.

2) All ideas contributed will be anonymous - to control evaluation apprehension. 
3) We are assessing the ideas of individuals, not the group collectively - to control free-riding.

Once again, unlike other experiments, instead of just verbalising this information it was also included on the information sheet attached to the participant's desk so they could reference it when desired.

Once the background information was provided to the participants, they were asked to gather round one of the ThinkPad's which was running the Idea Generator software. While an audio recording played a description of the software (see Sect. 3.2 for software description) the experimenter pointed to the relevant parts of the screen.

The software was designed to externalise ideas in a textual form. While it could be argued that some aspects of design are more oriented towards sketching ideas rather than writing then, van der Lugt [22] argues how sketching and writing ideas are quite different in nature (i.e. brainsketching vs. brainstorming). van der Lugt [23] has shown how sketching causes a breakdown in the process of activities like brainstorming. To make a valid comparison with previous research [20], we controlled this confounding variable of representation by using a textual representation of ideas for all conditions.

The warm-up exercise was utilized to get the participants used to the experiment and the software they would be using. The exercise lasted two minutes and was based on an adaptation of the tourism problem [9] for the European community:

'Each year a great many European tourists go to America to visit. But now suppose that Europe wanted to get many more Americans to come to Europe during their vacations. What steps can you suggest to get many more Americans to come to Europe as tourists?'

The experimenter asked all the participants if they understood the problem and gave an example idea of 'providing cheaper trans-Atlantic flights'. Once all queries had been dealt with, the experimenter asked the participants to take a seat at a desk and open up the Idea Generator software. Once the experimenter was happy, the two minute warm-up exercise began.

After the two minutes all participants were asked to come to the back of the lab. The experimenter checked for erroneous responses, closed the Idea Generator software on each IBM ThinkPad and cleared the SQL Server of all ideas from the warm-up exercise. If the experimenter found erroneous responses, he explained to all the participants why this was so. After dealing with all queries by the participants and upon being satisfied that everyone was happy, the experimenter began the design problem experiment.

Unlike other experiments which gave non-specialist problems such as the tourist problem [9], it was decided to give a design problem within the domain of computer science, in order to relate the findings of the experiment more to design in that domain. The problem was named the Pervasive Computing Scrolling Problem and was like other design problems in that it was open-ended and ill-defined:

'You have been asked to design an interaction technique for scrolling on a pervasive computer system with a 61 " plasma screen. The technique should allow the user or users to scroll up, down, left and right.'

The experimenter asked all the participants if they understood the problem and answered any questions without giving information as to possible solutions to the 
problem. Once all queries had been dealt with, the experimenter asked the participants to take a seat at a desk and open up the Idea Generator software by selecting the appropriate icon on the desktop. Participants were then informed that they could remove a partial overlay on the information sheet that revealed the experimental problem. This allowed the participants to reference the problem as they worked. The experimenter told the participants that the experiment would last sixteen minutes. Before the experiment started the experimenter started recording the participants and then informed them that they could begin.

For those participants who were in the nominal-real or real-nominal condition, the experimenter changed the condition after eight minutes via the experimenter's computer. Upon the change in condition, the label on the participant's computer changed to indicate which condition the participant was in, and the experimenter also verbally communicated this from the experimenter's room to make the participants aware of the change in condition.

After the sixteen minutes were completed, the experimenter asked all participants to stop typing; close down the Idea Generator software; and remain seated. The experimenter then stopped the recording and handed each participant a questionnaire.

While the participants were completing the questionnaire, the experimenter printed off a form for a post-analysis of each participant's ideas. The post-analysis was designed to assess if the ideas generated were novel. Previous research [e.g. 16, 2531] considers every idea generated to be creative, however in order for an idea to be considered creative it must be both novel and appropriate [12]. The experimenter went round each participant and asked them to say for each of their ideas whether it was: (i) a new idea - a combination of two or more existing ideas; (ii) an old, existing idea applied to a new context; or (iii) other, and if other could they specify. This classification of ideas is similar to that used by Benami and Jin [10].

\section{Results}

The dependent variable we observed in the experiment was creativity. According to Torrance [24] we can measure creativity in terms of fluency, flexibility and quality. Fluency is the number of creative ideas that were generated. Flexibility is the number of categories of ideas that were generated. Quality is a subjective rating by two or more independent judges who are considered experts in the domain in question [14]. It is beyond the scope of this paper to analyse all these factors of creativity, therefore we are going to consider fluency as a factor of creativity.

We analysed the effect of the operational mechanisms upon creativity in terms of the number of creative ideas generated and the number of replicated ideas. The findings are reported in terms of the effect upon the individual and the group.

Most other studies when considering the number of creative ideas just assume every idea to be creative - taking into account replications. However, in accordance with our definition of creativity $[11,12]$, in order for an idea to be deemed creative we first assessed all generated ideas for their novelty by using the retrospective protocol administered after the experiment and then assessed all novel ideas to determine if they were appropriate. Appropriateness was determined using a simple checkbox list to make sure each idea conformed to the characteristics defined during 
the problem statement - the interaction techniques should allow the user or users to scroll up, down, left and right.

\subsection{The Effect of Operational Mechanisms on the Creativity of Individuals}

The number of novel and creative ideas was assessed for each participant. The mean number of novel and creative ideas, replicated and non-replicated, can be seen in table 1 .

Table 1. Mean (and SD) number of novel and creative ideas for all four conditions for individuals

\begin{tabular}{|l|c|c|c|c|}
\hline & $\mathrm{N}$ & $\mathrm{N}-\mathrm{R}$ & $\mathrm{R}-\mathrm{N}$ & $\mathrm{R}$ \\
\hline $\begin{array}{l}\text { Novel Ideas } \\
\text { (Replicated) }\end{array}$ & $10.08(3.34)$ & $8.5(2.24)$ & $12.08(4.77)$ & $10.25(4.33)$ \\
\hline $\begin{array}{l}\text { Novel Ideas } \\
\text { (Non-Replicated) }\end{array}$ & $7.08(4.31)$ & $6.17(2.79)$ & $9.75(3.94)$ & $9.25(3.91)$ \\
\hline $\begin{array}{l}\text { Creative Ideas } \\
\text { (Replicated) }\end{array}$ & $9.75(3.42)$ & $8.5(2.24)$ & $11.58(4.01)$ & $9(5.34)$ \\
\hline $\begin{array}{l}\text { Creative Ideas } \\
\text { (Non-Replicated) }\end{array}$ & $6.75(4.30)$ & $6.17(2.79)$ & $9.33(3.94)$ & $8(3.91)$ \\
\hline
\end{tabular}

The data were analysed using a one-way unrelated ANOVA. No significant differences were found between the four conditions: novel ideas, including replications $\left(\mathrm{F}_{3,44}=1.97, \mathrm{p}=0.133\right)$; novel ideas, with no replications $\left(\mathrm{F}_{3,44}=2.63, \mathrm{p}\right.$ $=0.062)$; creative ideas, including replications $\left(\mathrm{F}_{3,44}=1.43, \mathrm{p}=0.247\right)$; and creative ideas, with no replication $\left(\mathrm{F}_{3,44}=1.57, \mathrm{p}=0.210\right)$. Therefore, with respect to the effect of operational mechanisms on the creativity of individuals, hypothesis H1 was not supported.

Using these data, the number of replications made by individuals was calculated for both novel and creative ideas. The mean number of novel and creative ideas that were replicated can be seen in table 2 .

Table 2. Mean (and SD) number of replications for both novel and creative ideas for individuals

\begin{tabular}{|l|c|c|c|c|}
\hline & $\mathrm{N}$ & $\mathrm{N}-\mathrm{R}$ & $\mathrm{R}-\mathrm{N}$ & $\mathrm{R}$ \\
\hline Novel Ideas & $3(1.91)$ & $2.33(1.07)$ & $2.83(1.72)$ & $1(1.21)$ \\
\hline Creative Ideas & $3(1.91)$ & $2.33(1.07)$ & $2.25(1.66)$ & $1(1.21)$ \\
\hline
\end{tabular}

Using a one-way unrelated ANOVA, significant differences were found between the four conditions for both novel $\left(\mathrm{F}_{3,44}=3.67, \mathrm{p}=0.019\right)$ and creative $\left(\mathrm{F}_{3,44}=3.72, \mathrm{p}\right.$ $=0.018$ ) ideas. In order to detect where the significance occurred, we performed a Tukey Test. From the data for the number of replicated novel ideas we found that there was a significant difference only between the nominal and real group conditions (mean $\mathrm{N}-$ mean $\mathrm{R}=2, \mathrm{~T}=1.66,2>1.66, \mathrm{p}<0.05$ ). For the number of replicated creative ideas, we also only found there to be a significant difference between the nominal and real group conditions (mean $\mathrm{N}-$ mean $\mathrm{R}=2, \mathrm{~T}=1.64,2>1.64$, $\mathrm{p}<$ 0.05). Therefore, with respect to the effect of operational mechanisms on the 
creativity of individuals, hypothesis $\mathrm{H} 2$ was partially supported, as a significant effect was found between the nominal and real group conditions, but no significant effect was found between either the nominal or real group conditions and either the nominal-real or real-nominal conditions.

\subsection{The Effect of Operational Mechanisms on the Creativity of Groups}

The numbers of novel and creative ideas were assessed for each group. The mean number of novel and creativity ideas, replicated and non-replicated, can be seen in table 3 .

Table 3. Mean (and SD) number of novel and creative ideas for all four conditions for groups

\begin{tabular}{|l|c|c|c|c|}
\hline & $\mathrm{N}$ & $\mathrm{N}-\mathrm{R}$ & $\mathrm{R}-\mathrm{N}$ & $\mathrm{R}$ \\
\hline $\begin{array}{l}\text { Novel Ideas } \\
\text { (Replicated) }\end{array}$ & $41(3)$ & $34.33(2.31)$ & $49(13)$ & $40.33(10.41)$ \\
\hline $\begin{array}{l}\text { Novel Ideas } \\
\text { (Non-Replicated) }\end{array}$ & $26.33(4.61)$ & $25(2.31)$ & $38.67(7.57)$ & $36.33(8.50)$ \\
\hline $\begin{array}{l}\text { Creative Ideas } \\
\text { (Replicated) }\end{array}$ & $39.67(4.51)$ & $33.33(3.51)$ & $47.66(11.02)$ & $32.33(13.80)$ \\
\hline $\begin{array}{l}\text { Creative Ideas } \\
\text { (Non-Replicated) }\end{array}$ & $25.22(4.04)$ & $25(2.65)$ & $38(7.21)$ & $32.33(11.15)$ \\
\hline
\end{tabular}

The data were analysed using a one-way unrelated ANOVA. No significant differences were found: novel ideas, including replications $\left(\mathrm{F}_{3,8}=1.49, \mathrm{p}=0.298\right)$; novel ideas, with no replications $\left(\mathrm{F}_{3,8}=3.64, \mathrm{p}=0.064\right)$; creative ideas, including replications $\left(\mathrm{F}_{3,8}=1.21, \mathrm{p}=0.365\right)$; and creative ideas, with no replications $\left(\mathrm{F}_{3,8}=\right.$ $2.33, \mathrm{p}=0.151)$. Therefore, with respect to the effect of operational mechanisms on the creativity of groups, hypothesis H1 was not supported.

From this data, the number of replications made by the group for both novel and creative ideas was calculated. The mean number of novel and creative ideas that were replicated can be seen in table 4 .

Table 4. Mean (and SD) number of replications for both novel and creative ideas for groups

\begin{tabular}{|l|c|c|c|c|}
\hline & $\mathrm{N}$ & $\mathrm{N}-\mathrm{R}$ & $\mathrm{R}-\mathrm{N}$ & $\mathrm{R}$ \\
\hline Novel Ideas & $14.66(5.51)$ & $9.33(0.58)$ & $10.33(5.69)$ & $4(2)$ \\
\hline Creative Ideas & $14.33(5.03)$ & $8.33(1.16)$ & $8.66(5.03)$ & $3(2.65)$ \\
\hline
\end{tabular}

Using a one-way unrelated ANOVA, no significant differences were found between the four conditions for novel ideas $\left(\mathrm{F}_{3,8}=3.44, \mathrm{p}=0.072\right)$, but significant differences were found between the four conditions for creative ideas $\left(\mathrm{F}_{3,8}=4.36, \mathrm{p}=\right.$ 0.043). To detect where the significance occurred between the conditions for the number of replicated creative ideas, we performed a Tukey Test. For the number of replicated creative ideas, we found there to be a significant difference between the nominal and real group conditions (mean $\mathrm{N}-$ mean $\mathrm{R}=11.33, \mathrm{~T}=10.04,11.33>$ 
$10.04, \mathrm{p}<0.05)$. Therefore, with respect to the effect of operational mechanisms on the creativity of groups, hypothesis $\mathrm{H} 2$ was also partially supported, as a significant effect was found between the nominal and real group conditions, but no significant effect was found between either the nominal or real group conditions and either the nominal-real or real-nominal conditions.

\section{Discussion}

A lot of research [e.g. 16, 25-31] over the years has explored how to reduce the impact of social influences upon creativity in collaborating groups - removing the factors of production blocking, evaluation apprehension and free riding. However, the findings of such research have only increased the effectiveness of real groups over nominal groups slightly in some conditions, while in many cases nominal groups continue to outperform real groups. In this study, we built on previous research to reduce the social influences upon creativity to see what the effect of the various operational mechanisms would be without the social influences acting as confounding variables.

Creativity in terms of fluency - the number of creative ideas generated - was assessed as a result of altering the operational mechanism from the perspective of the individual and the group. In addition to looking at the fluency of creativity, we also analysed the number of replicated ideas for both novel and creative ideas. It was hypothesized that: the number of creative ideas generated in response to a given design problem would be greater when participants worked in the nominal-real condition rather than working in either a real, nominal or real-nominal condition (H1); and that the nominal condition would generate more replicated ideas compared to the other conditions and the real condition would generate fewer replicated ideas compared to other conditions (H2).

We found that there were no statistically significant differences between any of the four conditions in terms of the fluency of creativity for both individuals and groups; therefore $\mathrm{H} 1$ was not supported. This is in itself an important finding since, compared to the large body of previous research [e.g. 16, 25-31], we substantially increased the creative performance of real groups. We produced a change from the creativity of real groups being statistically less significant than that of nominal groups, as reported by previous studies, to there being no statistical differences between these conditions.

The experimental hypothesis H1 was based on our theory [12] that real groups should be able to generate more creative ideas due to more effective sharing of domains of knowledge. Despite our increasing the creative performance of real groups, we did not confirm the experimental hypothesis that the nominal-real condition should be most creative. Hence, we must ask why there were no statistically significant differences in creativity due to different operational mechanisms as predicted?

So, why is it the case that real groups still did not reach their theoretical potential when social influences upon creativity were removed in our study? The representation of the externalization of matrices of knowledge (i.e. a list of ideas represented as text) may not have been effective enough. Other possible explanations relate to the time taken by the participants. Perhaps the time allowed was sufficient 
for the participants in each of the conditions to reach their maximum threshold of productivity, therefore being equally productive across conditions; or it could also have been the case that participants were suffering from fatigue and had lost the motivation to continue [14]. Our experiment followed Rotter's [20] which assumed that a 16-minute session is equivalent to 28 -minute sessions. That is, the nominal and real conditions each ran for an uninterrupted 16 minutes while the nominal-real and real-nominal conditions each had a change in operational mechanism halfway through the session. The changeover may have had effects on the participants' creativity. While the change itself was minimally disruptive, as described above, each participant in the nominal-real condition was suddenly faced at the beginning of the real sub-condition with the accumulated ideas from the other participants in the nominal sub-condition. The participants may have concentrated on "catching up" on the others' ideas, thus incurring a form of production blocking. To explore these potential explanations for our results, further research is required.

It was also found that there were statistically significant differences between the nominal group condition and the real group condition for the number of replicated ideas, supporting hypothesis $\mathrm{H} 2$ for both the effect on the individual and the group. Rotter et al [20] argued that the expression of an idea in a group causes all the members to think along the same lines, leading to the duplication of ideas. However, this study has contradicted Rotter et al [20], as real groups replicated fewer ideas than nominal groups. It was also no surprise that there were no statistically significant differences between the nominal-real and the real-nominal group conditions, since each condition had an equal amount of time in the nominal condition and the real condition - therefore the effects of replicated ideas for each condition could have cancelled each other out. It is possible that statistically significant differences were found only between the nominal and real group conditions because of the effects of increasing and decreasing duplicated ideas respectively for each condition. Yet when comparing either the nominal or real group conditions with either the nominal-real or real-nominal conditions, there were no significant differences.

Therefore, although we have shown that there is no statistically significant difference between the fluency of creativity when considering the effects of operational mechanisms in terms of individuals and groups, we have shown a significant change in the perform of real groups compared to previous research [e.g. $16,25-31]$ and also shown real groups to be more effective during the design process compared to the nominal group compositions, when social influences upon creativity are controlled. Hence, our findings have contradicted an abundance of previous research [e.g. 16, 25-31] showing real groups to be inferior to nominal groups.

\section{Conclusions and Future Work}

In this paper we report an experiment investigating the effect of operational mechanisms on creativity from the perspective of both the individual and the group in a design scenario. In the experiment we manipulated operational mechanisms that consisted of four levels: nominal; nominal-real; real-nominal; and real group conditions. 
The results of the experiment are that there was no significant difference in creativity between any of the conditions although a significant change in performance has been found compared to other research, and significant differences were found when looking at the number of replicated ideas, showing real groups to be more efficient in terms of the number of non-replicated ideas - refuting an abundance of previously reported research [e.g. 16, 25-31].

In our future work we plan to conduct further analyses of the data: assessing creativity between the different conditions in terms of flexibility and quality. In addition to this, we are also going to analyse the performance of the individuals' and groups' creativity.

Further research questions which we have so far identified from the analysis presented in this paper are: why is it the case that real groups are still not reaching their theoretical potential when social impediments to creativity are removed?; does the form of representation of externalized matrices of knowledge affect creativity; and is it the case that there is an upper limit on a person's creative productivity before task motivation falls below some threshold and fatigue sets in?

With answers to such research questions, we can look towards supporting social creativity and improving the practice of design, ultimately leading to more usable and useful software applications and computer systems.

\section{References}

1. Floyd, C., Mehl, W., Reisen, F., Schmidt, G. \& Wolf, G. Out of Scaninavia: alternative approaches to software design and system development. Human-Computer Interaction 4 (1989) 253-350

2. O'Neill, E. User-developer cooperation in software development: building common ground and usable systems. Springer Verlag, London (2000)

3. Alborzi, H., Druin, A., Montemayor, J., Platner, M., Porteous, J., Sherman, L., Boltman, A., Taxén, G., Best, J., Hammer, J., Kruskal, A., Lal, A., Schwenn, T. P., Sumida, L., Wagner, R., \& Hendler, J., Designing StoryRooms: Interactive Storytelling Spaces for Children. in DIS (Brooklyn, New York, 2000) 95-104

4. Buur, J. \& Bødker, S., From Usability Lab to "Design Collaboratorium": Reframing Usability Practice. in DIS (Brooklyn, New York, 2000) 297-307

5. Bødker, S. \& Iverson, O. S., Staging a Professional Participatory Design Practice - Moving PD beyond the Initial Fascination of User Involvement. in NordiCHI (Arhus, Denmark, 2002) 11-18

6. Kyng, M., Scandinavian Design: Users in Product Development. in CHI (Boston, Massachusetts, 1994) 3-9

7. Shneiderman, B. Creating Creativity: User Interfaces for supporting innovation. ACM Trans. on Computer-Human Interaction, 7,1 (2000) 114-138

8. Streitz, N., Geißler, J., Holmer, T., Konomi, S., Müller-Tomfolde, C., Reischl, W., Rexroth, P., Seitz, P. \& Steinmetz, R., I-LAND: An interactive Landscape for Creativity and Innovation. in CHI (Pittsburgh, PA, 1999) 120-127

9. Taylor, D.W., Berry, P. C. \& Block C. H. Does Group Participation When Using Brainstorming Facilitate or Inhibit Creative Thinking? Administrative Science Quarterly, 3, 1 (1958) 23-47 
10. Benami, O. \& Yan, J., Creative Stimulation in Conceptual Design. in ASME Design Engineering Technical Conferences and Computer and Information in Engineering Conference (Montreal, Canada, 2002) 1-13

11. Warr, A. \& O'Neill, E., Getting Creative with Participatory Design. in Participatory Design Conference, 2 (Toronto, Canada, 2004) 57-60

12. Warr, A. \& O'Neill, E., Understanding Design as a Social Creative Process. in Creativity and Cognition (London, UK, 2005)

13. Boden, M. The Dimensions of Creativity. MIT Press Cambridge, London (1994)

14. Amabile, T.M. The Social Psychology of Creativity. Springer-Verlag, New York (1983)

15. Guildford, J.P. Creativity. American Psychologist, 5 (1950) 444-454

16. Mullen, B., Johnson, C. \& Salas, E. Productivity Loss in Brainstorming Groups: A MetaAnalytic Integration. Basic and Applied Social Psychology, 12, 1 (1991) 3-23

17. Osborn, A.F. Applied Imagination: Principles and procedures of creative thinking. Scribeners and Sons, New York (1957)

18. Diehl, M. \& Stroebe, W. Productivity Loss in Brainstorming Groups: Toward the Solution of a Riddle. Journal of Personality and Social Psychology, 53 (1987) 497-509

19. Lamm, H. \& Trommsdorff, G. Group versus individual performance on tasks requiring ideational proficiency (brainstorming). European Journal of Social Psychology, 3 (1973) 361-387

20. Rotter, G.S. \& Portugal, S. M. Group and Individual Effects in Problem Solving. Journal of Applied Psychology, 53, 4 (1969) 338-341

21. Terry, D.J. \& Hoog, M. A. Attributes, behavior and social context the roles of norms and group membership. Lawrence Erlbaum Associates, Mahwah, NJ (2000)

22. van der Lugt, R., Functions of Sketching in Design Idea Generation Meetings. in Creativity and Cognition (Loughborough, UK, 2002) 72-79

23. van der Lugt, R. Developing a graphic tool for creative problem in design groups. Design Studies, 21, 5 (2000) 505-522

24. Torrance, E.P. Influence of Dyadic Interaction on Creative Functioning. Psychology Reports, 26 (1970) 391-394

25. 25. Cohen, D., Whitmyre, J. W. \& Funk, W. H. Effect of Group Cohesiveness and Training upon Creative Thinking. Journal of Applied Psychology, 44, 5 (1960) 319-322

26. Demhis, A.R. \& Valacich, J. S. Computer Brainstorms: More Heads Are Better Than One. Journal of Applied Psychology, 78, 4 (1993) 531-536

27. Dillon, P.C., Graham, W. K. \& Aidells, A. L. Brainstorming on a "Hot" Problem: Effects of Training and Practice on Individual and Group Performance. Journal of Applied Psychology, 56, 6 (1972) 487-490

28. Kraemer, T.J., Fleming, G. P. \& Mannis, S. M. Improving Face to Face Brainstorming through Modelling and Facilitation. Journal of Small Group Research, 32, 5 (2001) 533557

29. McGlynn, R.P., McGurk, D., Effland, V. S., Johll, N. L. \& Harding, D. J. Brainstorming and Task Performance in Groups Contained by Evidence. Journal of Organisational Behaviour \& Human Decision Processes, 93, 1 (2004) 75-87

30. Paulus, P.B. \& Yang, H. Idea Generation in Groups: A Basis for Creativity in Organisations. Journal of Organisational Behaviour \& Human Decision Processes, 82, 1 (2000) 76-87

31. Valacich, J.S., Dennis, A. R. \& Connolly, T. Idea Generation in Computer-Based Groups: A New Ending to an Old Story. Journal of Organisational Behaviour \& Human Decision Processes, 57, 2 (1994) 448-466 